Chirurgia (2021) 116: 431-437

No. 4, July - August

Copyright@ Celsius

http://dx.doi.org/10.21614/chirurgia.116.4.431

\title{
Robotic-assisted Laparoscopic Liver Resections - Technical Considerations for da Vinci Xi
}

\author{
Nita Thiruchelvam', Adrian K.H. Chiow', Lee Lip Seng', Olexii Potapov², Marco V. Marino3,4* \\ 'Department of General Surgery, Hepatopancreatobiliary Service, Changi General Hospital, Singapore \\ ${ }^{2}$ Center for Innovative Medical Technologies of the National Academy of Sciences of Ukraine, Kiev, Ukraine \\ ${ }^{3}$ Department of General and Emergency Surgery, Azienda Ospedaliera Ospedali Riuniti Villa Sofia-Cervello, Palermo, Italy \\ ${ }^{4}$ Department of General and Oncologic Surgery, Università degli Studi di Palermo, Palermo, Italy
}

${ }^{*}$ Corresponding author: Marco V. Marino, MD PhD FEBS FACS FICS

Department of General and Emergency Surgery, Azienda Ospedaliera Ospedali Riuniti Villa Sofia-Cervello, Palermo, Italy E-mail:marco.vito.marino@gmail.com

\section{Rezumat}

Rezecții hepatice robotice - consideratii tehnice pentru sistemul chirurgical robotic da Vinci Xi

Pe măsură ce abordarea laparoscopică devine din ce în ce mai obişnuită pentru rezecțile hepatice, mai multe centre au adoptat abordarea robotică pentru numeroasele sale beneficii ce constau în principal în vedere mărită şi stabilă, articulare intuitivă a instrumentului, filtrare a tremurului. In acest articol subliniem consideratiile tehnice specifice rezectiilor hepatice robotice realizate cu sistemul chirurgical robotic da Vinci Xi.

Cuvinte cheie: rezecția robotică a ficatului, chirurgie minim invazivă

\section{Abstract}

As laparoscopic approach becomes increasingly routine for liver resections, several centers have also adopted the robotic approach for its many purported benefits of magnified steady views, intuitive instrument articulation, and tremor filtration amongst others. In this article we highlight the technical considerations specific to robotic-assisted laparoscopic liver resections for the da Vinci robotic Xi Surgical System.

Key words: robotic liver resection, minimally invasive surgery 


\section{Introduction}

The adoption of laparoscopy in liver resection has surged in the recent decade with more surgeons mounting the learning curve as strong evidence emerged demonstrating improved short-term outcomes such as blood loss and length of hospitalization with similar oncological outcomes (1-3). As the robot becomes increasingly accessible to centers world-wide, many centers have reported their outcomes demonstrating comparable outcomes of liver resections performed robotically and laparoscopically $(4,5)$. The most recent international consensus statement on robotic hepatectomy in 2018 concluded that it is as safe and feasible for both major and minor hepatectomy when compared with laparoscopic or open resections (6). The shorter learning curve associated with robotic surgery in comparison with laparoscopic surgery may be a pull factor for increased adoption of robotics in liver resection $(7,8)$. In this article, we highlight the technical considerations for RAL liver resections using the da Vinci Robotic Xi Surgical System (Intuitive Surgical, Sunnyvale, CA, USA).

\section{Operation Theater Set-Up}

Having a routine set-up in the operation theater is paramount to facilitate smooth liver surgery. The set-up should take into account easy docking of the robot, ergonomic positioning of the bedside assistant and allow for constant ready access of the anesthetist to the patient's airway and vascular lines. A spacious operation theater is recommended.

Similar to the set-up in the laparoscopic approach, the patient is often positioned in a reverse Trendelenburg ranging from 10-30 degrees, supine with split straight legs (9-11) (Fig. 1). This positioning is utilized even for resections involving the posterior superior segments as alternative positions such as left semi-lateral decubitus may not allow for adequate spacing between each robotic port.

The left arm is tucked in to facilitate docking of the patient cart of the robot. The bedside assistant stands between the patient's legs thereby allowing access to the robotic arms for efficient exchange of equipment and at the same time accessibility to the assistant port. A second optics display is an option if there is space limitation for the optimal placement of the vision cart. A typical operation theater set-up is demonstrated in Fig. 2.

\section{Port Positioning}

There are several variations to port positioning for RAL liver resections depending on the planned segments for resection. In a resection involving anterior segments, or a right hepatectomy, a $12 \mathrm{~mm}$ port is often utilized as the assistant port and is often placed at the umbilicus. Additional $8 \mathrm{~mm}$ robotic ports are positioned $6-8 \mathrm{~cm}$ apart in a linear plane perpendicular to the target anatomy, to allow for adequate triangulation and to avoid clashing of the robotic arms. The camera is often placed in arm 2 (R2) such that the main working robotic arms are arms 1 (R1) and 3 (R3), with the fourth robotic arm (R4) used mainly for retraction (Fig. 3). In a left sided resection, the camera may be placed in R3, whilst the main working ports are R2 and R4,

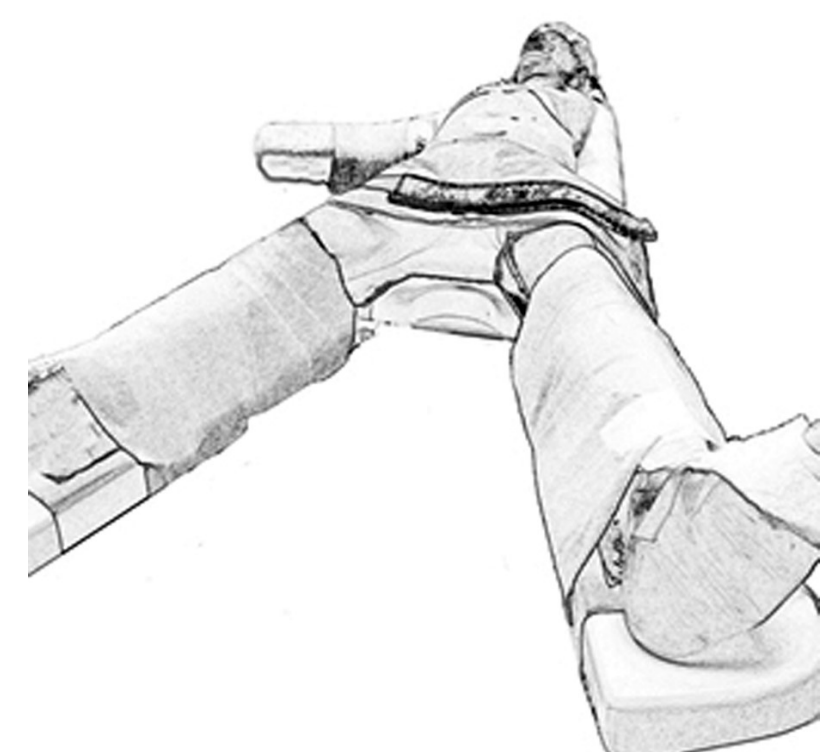

Figure 1. Supine straight split-leg position (9) https://creativecommons.org/licenses/by/4.0/ 


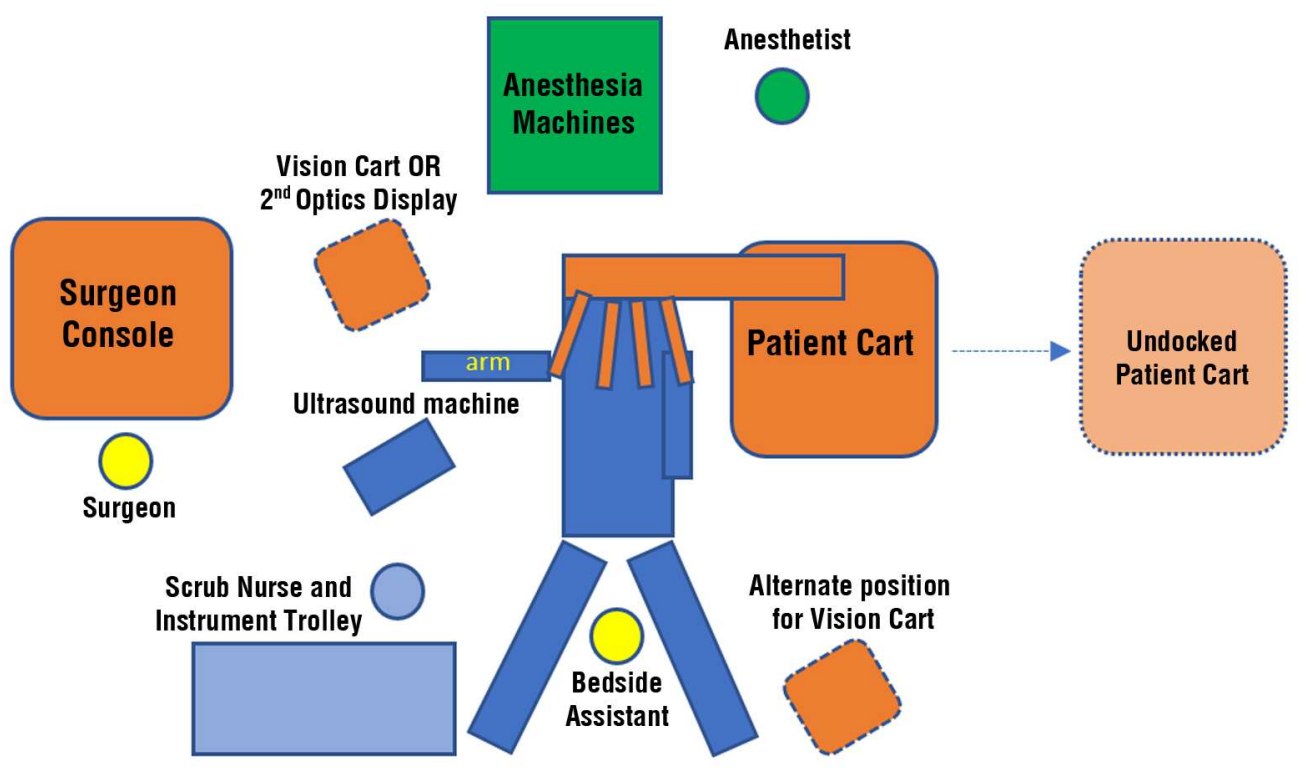

Figure 2. Operation Theatre Set-up

with $\mathrm{R} 1$ utilized mainly for retraction.

The assistant port is usually more caudally positioned to allow for the assistant to freely introduce instruments without being limited

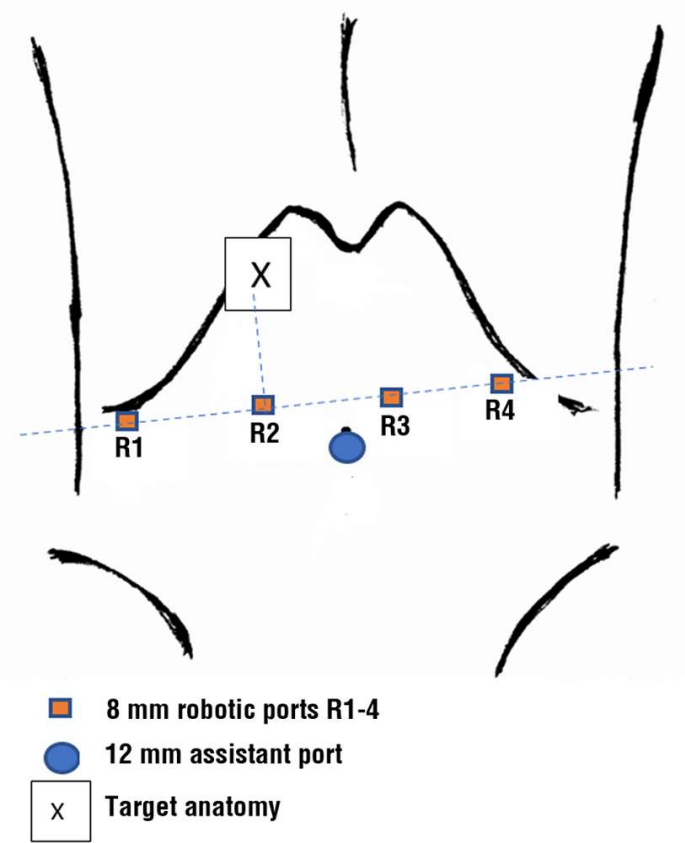

Figure 3. Typical port positioning in RAL liver resection for the da Vinci Robotic Xi Surgical System (Intuitive Surgical, Sunnyvale, CA, USA) by the robotic arms. Space is required as the assistant usually facilitates insertion of the ultrasound probe and where necessary, stapler devices. An additional $5 \mathrm{~mm}$ port may be placed for extra-corporeal Pringle's maneuver if deemed necessary.

When additional reach is required for posterior superior segments, the port positions will need to be globally shifted closer to the costal margin to allow for the instruments to reach to subdiaphragmatic area.

For combined single stage liver and colon resection, the positioning of the ports can be modified to accommodate both surgeries and minimize the total number of ports required. This is possible with the da Vinci $\mathrm{Xi}$ as the boom can rotate such that the direction of the robotic arms can be adjusted to facilitate multiquadrant surgeries with easy re-docking (12).

\section{Lesion Localization}

Intra-operative ultrasound (IOUS) after liver mobilization is still the mainstay of lesion localization. The ultrasound probe is controlled and inserted by the bedside assistant through the $12 \mathrm{~mm}$ assistant port. TileProTM multi-input display allows for 


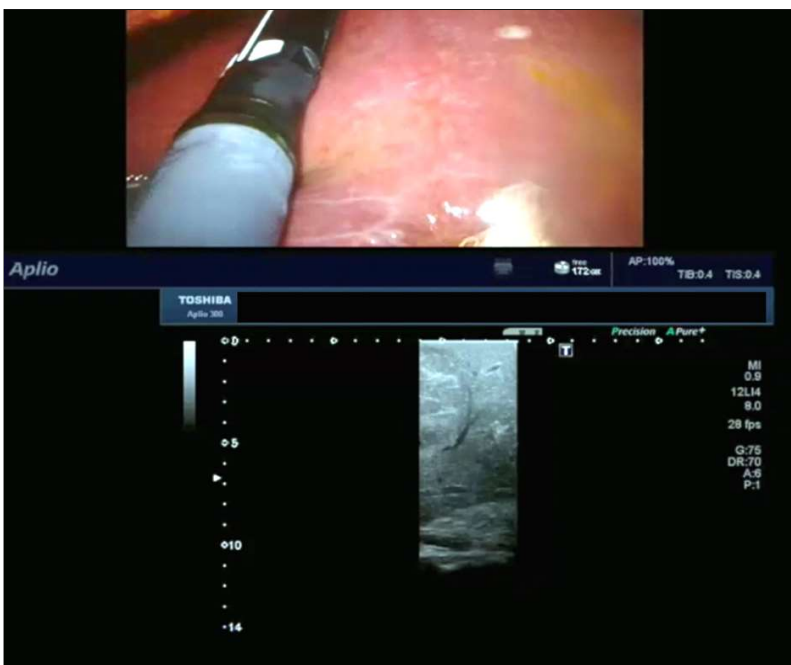

Figure 4. Integrated IOUS image on surgeon console and vision cart display

seamless integration of the ultrasound images onto the display for both the assistant and the console surgeon (Fig. 4).

Another game-changer in lesion localization is the use of the da Vinci's Firefly modeTM which is an integrated near-infrared (NIR) fluorescence imaging feature that can be activated directly on the surgeon console. In the context of liver resection, pre-operative systemic indocyanine green (ICG) dye administration results in residual staining of the pathological liver lesions. As ICG clearance is impaired in malignant hepatocytes or liver tissue that is compressed by tumor, fluorescence patterns of total staining are seen in hepatocellular carcinoma, whilst rim-staining is seen in other lesions such as colorectal liver metastases respectively (Fig. 5).

NIR ICG fluorescence is particularly useful in the detection of lesions close to the liver capsule, and may come in useful when used in conjunction with IOUS especially in cirrhotic livers where nodularity increases the difficulty in lesion detection. The first case series of RAL hepatic resections evaluating the application of ICG fluorescence imaging was published by Marino et al. who detected $11.5 \%$ new malignant lesions that were not picked up by pre-operative CT, MRI, or IOUS (13). Having said that, false-positive rates are also a concern as benign pathologies such as steatosis and hemangioma may also retain ICG.

\section{Parenchymal Transection}

\section{ICG demarcation}

After mobilization of the liver and identification of lesions, parenchymal transection can then proceed. NIR ICG in positive or negative staining may be used in anatomical segmental
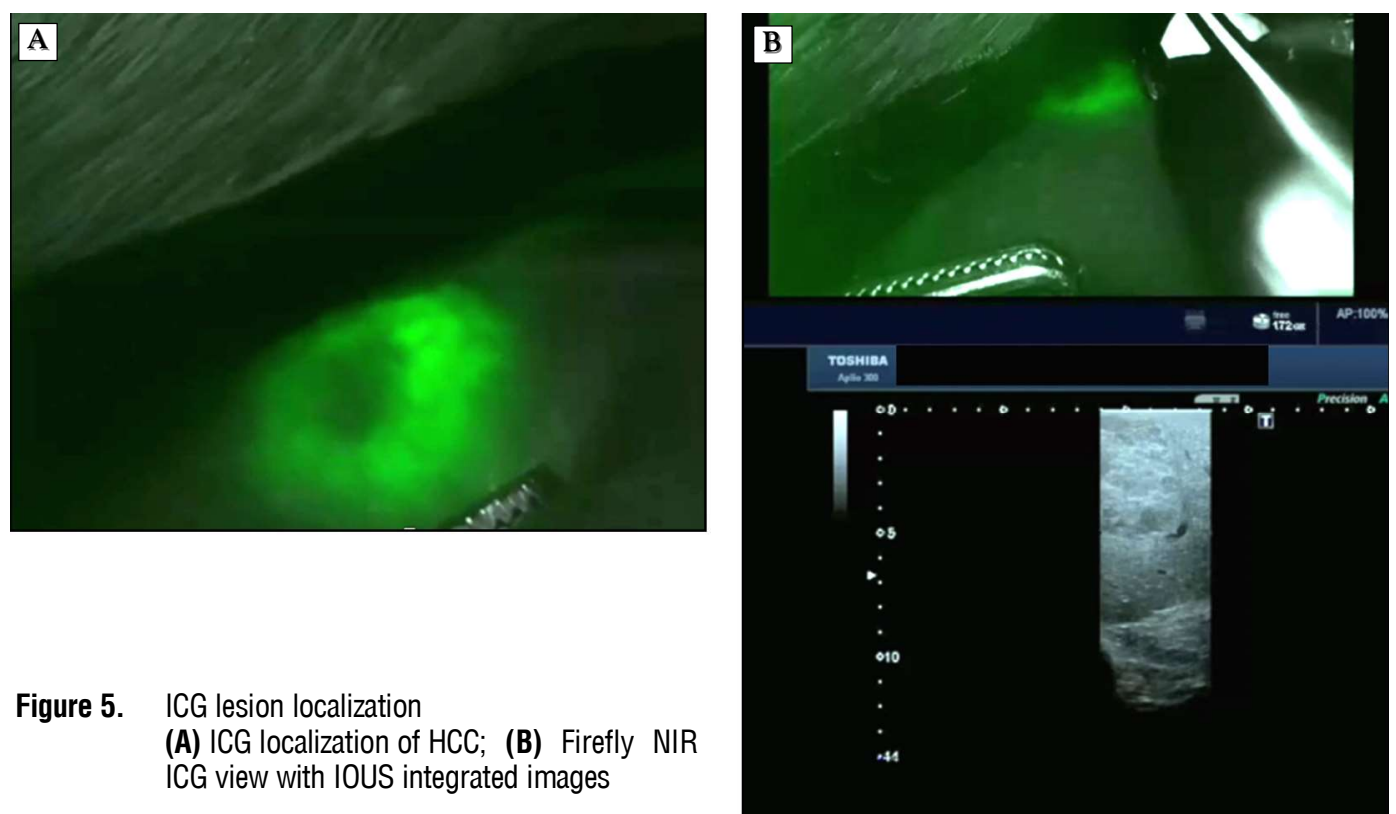

Figure 5. ICG lesion localization

(A) ICG localization of HCC; (B) Firefly NIR ICG view with IOUS integrated images 




Figure 6. ICG demarcation line for right hepatectomy

resections to provide greater distinction between ischemic lines. In positive staining, the inflow pedicle to the segment of interest is injected with ICG, a technique first described by Makuuchi et al. in open resections (14), and subsequently adopted in laparoscopy. The challenges in precise dissection of the inflow pedicle and injection of ICG faced during laparoscopy can be overcome with the use of wristed and articulating dissecting instruments in RAL surgeries. In negative staining, ICG is administered intra-venously after the inflow pedicles have been clamped or divided. ICG has been shown to provide clearer demarcation lines compared with the traditional ischemic line, especially in cirrhotic livers (15) (Fig. 6). In particular, in case of cirrhotic liver, the ICG seems to provide an evident advantage over IOUS, in this setting in fact the performance of IOUS is impaired due to the presence of regenerative nodule or irregular liver surface which renders it challenging and time consuming. Lastly, the applications of ICG in patients who should undergo multiple liver resections offers great benefits in terms of parenchymal-sparing technique thus tailoring and modulating the surgical resection margins.

ICG given intraoperatively for anatomical resections can also be used to guide visualization of the biliary tree. The junction between the right and left hepatic duct can be visualized to guide transection with NIR ICG via firefly (Fig. 7).

\section{Rubber-band retraction}

As the robotic Harmonic ACETM scalpel is

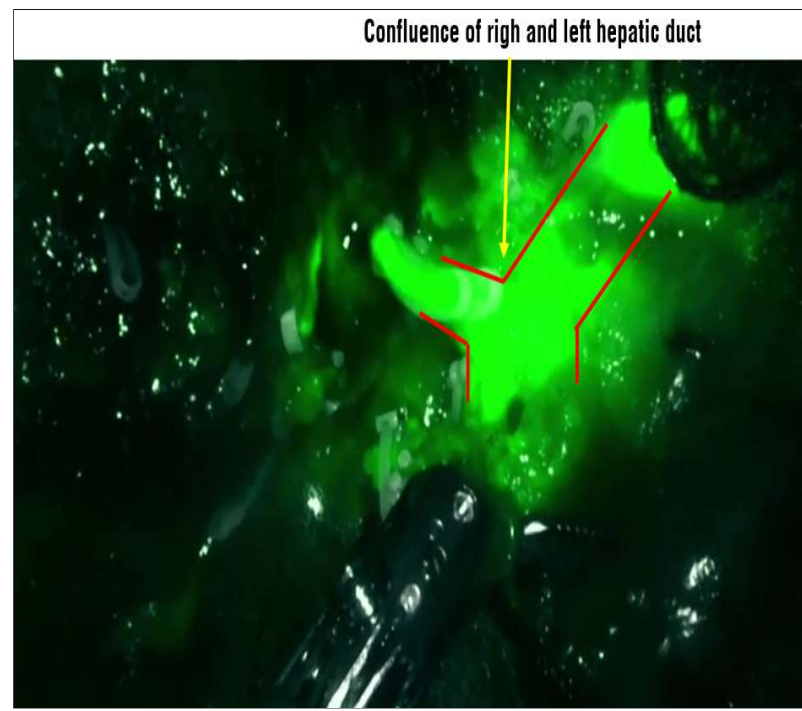

Figure 7. ICG visualization of right and left hepatic duct confluence

non-articulating, the cut-line along the liver should ideally be mobilized such that it is accessible from the robotic ports. Where necessary, the robotic arm can be exchanged to facilitate approach of the dissecting arm from a more ergonomical angle. Rubber-band retraction of the liver to splay open the cutline is useful to achieve this. This technique was adopted initially in laparoscopic liver resection and utilized again in the robotic approach by Choi et al. (16). In this technique, a rubber band is sutured onto the liver surface on each side of the cut-line and exteriorized through the abdominal wall - this allows the tension to be gradually manually adjusted by the bedside assistant as the transection progresses, such that a constant open-book view is obtained. The benefit of rubber-band retraction is that it frees up the third robotic arm to assist in the dissection (Fig. 8).

\section{Kelly-clysis technique}

In RAL hepatectomy, the basis of parenchymal transection is the Kelly-clysis technique that can be achieved using the articulating bipolar forceps in combination with the robotic Harmonic ACETM scalpel. The scalpel utilizes ultrasonic waves to coagulate protein and generates heat in vibrating tissue, thereby coagulating small blood vessels. Some centers report the additional use of the laparoscopic 


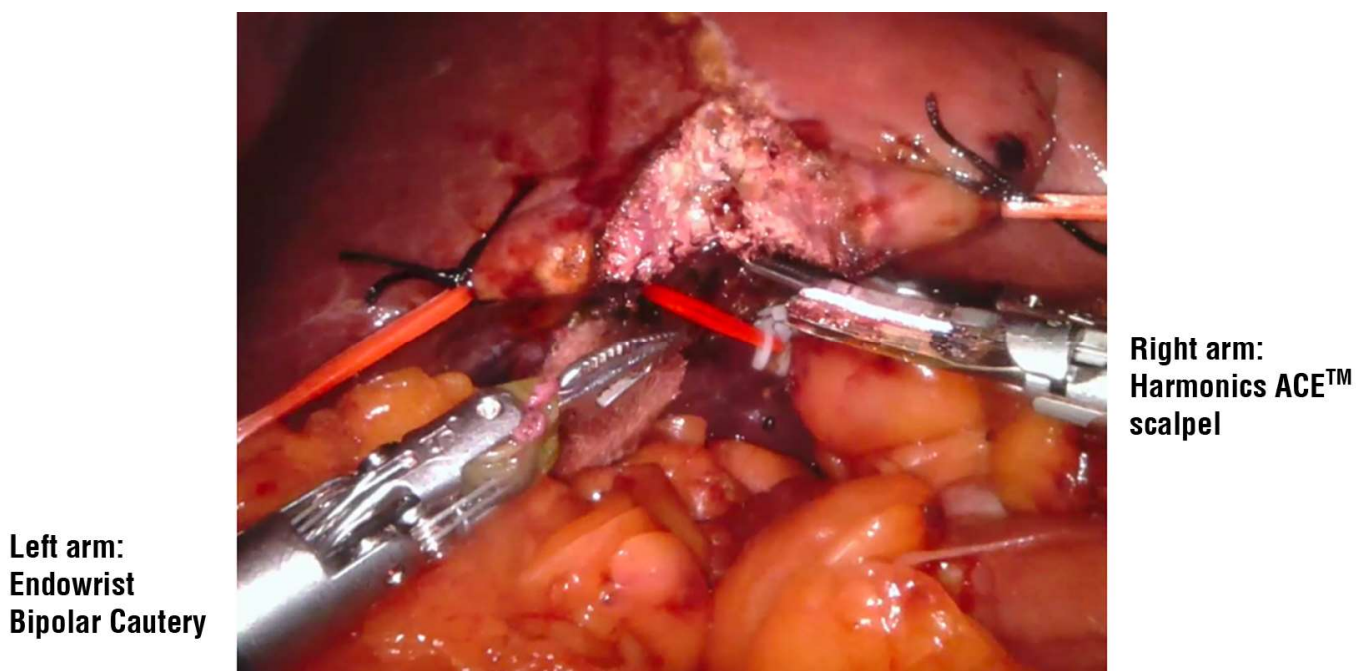

Figure 8. Rubber band retraction in RAL liver resection

Cavitron Ultrasonic Surgical Aspirator (CUSA; Valleylab, Boulder, CO, USA) through the assistant port, controlled by the bedside assistant, which may be particularly useful in long parenchymal transection lines to allow for quicker transection or in complex resections for dissection around major vascular structures (10). The need for a skilled bedside assistant to facilitate this remains the limitation of RAL liver resection as there is currently no robotic CUSA arm available.

\section{Posterior superior lesions}

RAL has been reportedly useful in particular for parenchymal preservation surgery involving the posterior superior lesions $(17,18)$. The articulating arms of the bipolar forceps allow for more precise transection and the stable retraction from a robotic arm coupled with the steady laparoscope view enhances the access to this difficult region. This may allow the surgeon to avoid the use of intercostal or trans-thoracic ports, and minimize need for a larger right sided resection such as a posterior sectionectomy or even a right hepatectomy.

\section{Discussion}

Whilst the robot has introduced remarkable benefits in the world of minimally invasive surgery with intuitive articulating instruments, tremor filtration, stable laparoscopic views and improved magnified views with integrated ICG fluorescence and intra-operative ultrasound imaging, its adoption remains slow for liver resection. Limitations to the robot are largely access-related due to cost issues, and are likely only to be available in high volume centers at the moment.

Although some centers describe shorter learning curves for RAL liver resection, this has been in the hands of experienced laparoscopic liver surgeons in high volume centers $(7,8)$. The use of a dual surgeon console would help in proctorship whilst surgeons mount their learning curve; however, this also comes with increased cost to obtain a second surgeon console. The use of formal mentorship and skills simulation programmes have been useful to decrease the learning curve in robotic proficiency (19).

The recent introduction of the da Vinci Vessel SynchroSealTM and Sealer ExtendTM may prove useful in RAL liver resection as their articulating arms allow for more precise dissection, transection, and sealing of vessels as parenchymal transection proceeds. As technology advances, introduction of robotic CUSA arm may further encourage the adoption of RAL liver resection.

Current available literature shows 
comparable short-term outcomes as well as oncological outcomes. Further large volume comparison studies are required to demonstrate efficacy and also cost-effectiveness of RAL liver resection in comparison with the laparoscopic approach.

\section{Conclusion}

RAL liver resection has a promising future in the hands of experienced MIS surgeons as it has its own range of technical benefits that currently surpass laparoscopy. As technology continues to improve to overcome the current limitations, it is likely to be increasingly adopted by centers worldwide.

\section{Conflict of Interest}

The authors declare no conflicts of interests.

\section{References}

1. Ciria R, Cherqui D, Geller DA, Briceno J, Wakabayashi G. Comparative short-term benefits of laparoscopic liver resection: 9000 cases and climbing. Ann Surg. 2016;263(4):761-77.

2. Goh BKP, Lee SY, Teo JY, Kam JH, Jeyaraj PR, Cheow PC, et al. Changing trends and outcomes associated with the adoption of minimally invasive hepatectomy: a contemporary single-institution experience with 400 consecutive resections. Surg Endosc. 2018;32(11):4658-65.

3. Goh BKP, Lee SY, Koh YX, Kam JH, Chan CY. Minimally invasive major hepatectomies: a Southeast Asian single institution contemporary experience with its first 120 consecutive cases. ANZ J Surg. 2020;90(4):553-7.

4. Nota CL, Rinkes IHB, Molenaar IQ, van Santvoort HC, Fong Y, Hagendoorn J. Robot-assisted laparoscopic liver resection: a systematic review and pooled analysis of minor and major hepatectomies. HPB. 2016;
18(2):113-20

5. Ho CM, Wakabayashi G, Nitta H, Ito N, Hasegawa Y, Takahara T. Systematic review of robotic liver resection. Surg Endosc. 2013;27(3):732-9.

6. Liu R, Wakabayashi G, Kim HJ, Choi GH, Yiengpruksawan A, Fong Y, et al. International consensus statement on robotic hepatectomy surgery in 2018. World J Gastroenterol. 2019;25(12):1432-44.

7. Efanov M, Alikhanov R, Tsvirkun V, Kazakov I, Melekhina O, Kim P, et al. Comparative analysis of learning curve in complex robot-assisted and laparoscopic liver resection. HPB. 2017;19(9):818-24.

8. Chen P, Wu C, Hu R, Chen C, Yuan R, Liang J, et al. Robotic major hepatectomy: is there a learning curve? Surgery. 2017;161:642-9.

9. Thiruchelvam N, Lee SY, Chiow AKH. Patient and port positioning in laparoscopic liver resections. Hepatoma Res 2021;7:22.

10. Kam JH, Goh BKP, Chan CY, Wong JS, Lee SY, Cheow PC, et al. Robotic hepatectomy: Initial experience of a single institution in Singapore. Singapore Med J. 2016;57(4):209-14.

11. Choi GH, Choi SH, Kim SH, Hwang HK, Kang CM, Choi JS, et al. Robotic liver resection: Technique and results of 30 consecutive procedures. Surg Endosc. 2012;26(8):2247-58.

12. Eu EW, Ngu JC, Chiow AKH. How to do a combined robotic anterior resection and liver resection: da Vinci Xi. ANZ J Surg. 2018:88(10):1076-7.

13. Marino MV, Podda M, Fernandez CC, Ruiz MG, Fleitas MG. The application of indocyanine green-fluorescence imaging during robotic-assisted liver resection for malignant tumors: a single-arm feasibility cohort study. HPB. 2020;22(3):422-31.

14. Makuuchi, M; Hasegawa, H; Yamazaki S. Ultrasonically guided subsegmentectomy. Surg Gynecol Obs. 1985;161(4):346-50.

15. Chiow AKH, Rho SY, Wee IJY, Lee LS, Choi GH. Robotic ICG guided anatomical liver resection in a multi-centre cohort: an evolution from "positive staining" into "negative staining" method. HPB. 2021;23(3): $475-82$

16. Choi GH, Chong JU, Han DH, Choi JS, Lee WJ. Robotic hepatectomy: the Korean experience and perspective. HepatoBiliary Surg Nutr. 2017;6(4): 230-8.

17. Tranchart H, Ceribelli C, Ferretti S, Dagher I, Patriti A. Traditional versus robot-assisted full laparoscopic liver resection: A matched-pair comparative study. World J Surg. 2014;38:2904-9.

18. Casciola L, Patriti A, Ceccarelli G, Bartoli A, Ceribelli C, Spaziani A. Robotassisted parenchymal-sparing liver surgery including lesions located in the posterosuperior segments. Surg Endosc. 2011;25:3815-24.

19. Al Abbas Al, Wang C, Hamad AB, Knab LM, Rice MK, Moser AJ, et al. Mentorship and formal robotic proficiency skills curriculum improve subsequent generations' learning curve for the robotic distal pancreatectomy. HPB (0xford). 2021;S1365-182X(21)00132-5. 